\title{
Does comprehensive geriatric assessment (CGA) in an outpatient care setting affect the causes of death and the quality of palliative care? A subanalysis of the age-FIT study
}

\author{
Jenny Dahlqvist ${ }^{1} \cdot$ Anne Ekdahl $^{2,3} \cdot$ Maria Friedrichsen $^{4,5}$ (D)
}

Received: 30 January 2019 / Accepted: 23 April 2019 / Published online: 8 May 2019

(c) The Author(s) 2019

\section{Key summary points}

Aim Does comprehensive geriatric assessment (CGA) affect the causes of death and the quality of palliative care when patients receive care at the end of life when in an outpatient care setting compared to usual care?

Findings CGA does not affect the causes of death. CGA affects the frequency of referral to specialised palliative care teams, but CGA does not affect the quality of palliative care given to the patients. These effects are measured in outpatient care settings and in comparison with usual care.

Message Further studies are needed to evaluate the CGA effects on causes of death and palliative care quality in outpatient care settings.

\begin{abstract}
Purpose The purposes of this study were to retrospectively study whether comprehensive geriatric assessment (CGA) given to community-dwelling old patients with high health care usage has effects regarding: (1) the cause of death and (2) the quality of the provided palliative care when compared to patients without CGA-based care.

Method This study includes secondary data from a randomised controlled trial (RCT) with 382 participants that took place in the periods 2011-2013. The present study examines all electronical medical records (EMR) from the deceased patients in the original study regarding cause of death [intervention group (IG) $N=51 /$ control group (CG) $N=66$ ] and quality of palliative care (IG $N=33 / \mathrm{CG} N=41$ ). Descriptive and comparative statistics were produced and the significance level was set at $p<0.05$.

Results The causes of death in both groups were dominated by cardiovascular and cerebrovascular diseases with no statistical difference between the groups. Patients in the intervention group had a higher degree of support from specialised palliative care teams than had the control group $(p=0.01)$.
\end{abstract}

Jenny Dahlqvist

jenny.dahlqvist@regionostergotland.se

1 Department of Geriatric Medicine, Vrinnevi Hospital, Gamla Övägen 25, 60182 Norrköping, Sweden

2 Geriatric Medicine, Department of Clinical Sciences Helsingborg, Helsingborg Hospital, Lund University, Charlotte Yhlens gata 10, 25187 Helsingborg, Sweden

3 Division of Clinical Geriatrics, Department of Neurobiology, Care Sciences and Society (NVS), Karolinska Institute (KI), Stockholm, Sweden

4 Department of Social and Welfare Studies, Linköping University, Norrköping, Sweden

5 Palliative Education and Research Center, Vrinnevi Hospital, Gamla Övägen 25, 60182 Norrköping, Sweden 
Conclusion The present study in an outpatient context cannot prove any effects of CGA on causes of death. The study shows that CGA in outpatient care means a higher rate of specialised palliative care, but the study cannot show any effects on the palliative quality parameters measured. Further studies with statistical power are needed.

Keywords Comprehensive geriatric assessment $\cdot$ Palliative care $\cdot$ Outpatient geriatric care $\cdot$ Mortality $\cdot$ Cause of death . End of life

\section{Introduction}

In Europe in 2014, the deaths among old people, over 65 years, were dominated by cerebrovascular and cardiovascular diseases, which answered for $40.4 \%$. Cancer caused $24.0 \%$ and respiratory diseases (including respiratory infections) caused $8.5 \%$ of deaths among people over 65 years of age [1]. The process of dying can be demanding and frightening and needs careful care planning. One way of doing this is by taking care of old, multi-morbid people according to comprehensive geriatric assessment (CGA). In 1991, Rubenstein defined CGA as a "multidisciplinary diagnostic process intended to determine a frail elderly person's medical, psychosocial, and functional capabilities and limitations to develop an overall plan for treatment and long-term followup" [2]. A recent review found out that this definition is still in use and that the "dimensions of CGA reported consistently included medical/physical, psychological/psychiatry, socioeconomic, function and nutritional assessment" [3]. Today, there are several studies in which CGA is used to predict mortality in, for example, hip fracture patients, heart failure patients, and hospitalized older patients in general [4-6], but the evidence of the effectiveness of CGA on mortality is diverse [7-12]. A meta-analysis from 1993 drew the conclusion that CGA-based care, given by a team controlling the medication and monitoring, improves survival rates, at least in the short term [11]. Another meta-analysis found reduced mortality at 6 and 8 months after discharge from CGA-based care but not before and after that period [7]. The latest Cochrane report from 2017 showed little or no evidence of reduced mortality when using CGA in an in-ward context [8]. A recent systematic review inventing effectiveness of in-hospital geriatric co-management found a trend of reduced in-hospital mortality, but the evidence was limited due to the invented studies having high risk of bias and heterogeneous measurement of outcomes [13]. Ekdahl et al. conducted a randomised controlled trial (RCT) with CGA in outpatient care over 24 months in which they found reduced mortality 36 months from baseline compared to conventional care [14]. Except for that study, we have not found any studies about how mortality is affected when CGA is used in an outpatient care setting. Therefore, it is interesting to conduct a subanalysis of the data from Ekdahl et al.'s study by including the patients that did not survive to compare the causes of death, in an effort to find out if CGA could affect this. A hypothesis was that CGA could affect the cause of death, which could be the key to why the mortality was reduced. It would also be interesting to see if CGA could affect the place, where the participants died and the quality of the palliative care given.

Care based on CGA has many similarities with palliative care. Palliative care is, like CGA, team-based and is based on a holistic approach [15]. Studies in palliative care/ palliative medicine usually target specialised palliative care in cancer and neurological diseases. Studies of patients dying from non-malignant conditions indicate the difficulties in predicting death when the final time is characterised by relapses of improvement and deterioration, where the underlying deterioration is easily hidden-"entry-reentry" [16]. Dying persons suffering from non-malignant diseases have the same need of specialised palliative care to control symptoms and to have open communication about death and dying as cancer patients have [17]. It is known that multimorbid old people suffer from a high symptom burden, especially pain $[18,19]$. It has also been shown that older people received poorer quality end-of-life-care than younger people [20]. Taking account of this knowledge, it is important to improve the palliative care also to older patients and patients suffering from non-malignant, but still potentially fatal diseases. There is, as far as we know, no study that has investigated the effect of CGA, in an outpatient context, on the quality of the provided palliative care. Our hypothesis was that the quality of provided palliative care would be higher in the intervention group than in the control group, as CGA is a holistic care approach which gives attention to the palliative needs. In summary, the purposes of this study were to retrospectively study whether CGA given to old patients with multi-morbidity in an outpatient context had effects regarding; (1) the cause of death-which could be an explanation of the reduced mortality and (2) the quality of the provided palliative care.

\section{Materials and methods}

\section{Design}

This is secondary data from a randomised controlled trial (RCT) investigating CGA-based care in an outpatient context in the intervention group and conventional care in the 
control group [14, 21, 22]. The present study contains a retrospective examination of all electronic medical records (EMRs) (Cambio Cosmic which contain records from all public care services in the region and private primary care services that are contracted to the public care services) for the participants in the original CGA-based study that died during the intervention period and up to 1 year afterwards, comparing causes of death and different aspects of palliative care. It is a per protocol analysis which means that the comparison is made only for those participants in the intervention group that really received the intervention [23].

\section{Setting}

The intervention took place in a municipality in the southeast of Sweden with approximately 130,000 inhabitants. The intervention started in 2011 and continued until the end of 2013. At the time of the intervention, most health care was provided at ten primary centres and one hospital (with 24-h admittance for surgical and medical emergencies). At the time for inclusion, the hospital had no CGA-based care at all why it is unlikely that the patients had been in contact with CGA before.

\section{Participants}

In the original RCT, 208 participants were allocated to the intervention group and 174 participants to the control group. At baseline everyone was 75 years or older and "living at home" (not in a nursing home). All participants had attended hospital for in-patient hospital care at least three times within the last 12 months and all had at least three diagnoses from different diagnosis groups according to International Statistical Classification of Diseases and Related Health Problems (ICD 10) (the Swedish definition of multi-morbid old people) [22]. In the original study, the intervention group got CGA-based care for the project period of 24 months. It is not likely that the quality of palliative care could be affected after the intervention was discontinued when the intervention group no longer received CGA-based care, which is why these aspects of the study are only investigated up to 24 months. Thus, this paper studies two populations: (1) at follow-up at the end of the intervention (24 months), 74 participants had died [intervention group (IG) $N=33 /$ control group (CG) $N=41]$. These persons were the study group for the retrospective study of palliative care. (2) At followup after 36 months in total, 117 participants had died (IG $N=51 / \mathrm{CG} N=66$ ). These persons were the study group for the retrospective study of causes of death (Fig. 1). As the original study reported reduced mortality after 36 months in the intervention group, the cause of death in this study was analysed up to 36 months [14]. In the original study, the intervention ended when the participant moved to a nursing home, i.e., participants were excluded from the palliative care aspects in both the intervention group and control groups, as the care was no longer CGA based. In the original study, all outcomes (including mortality) were analysed as 'Intention to treat' why participants moving to nursing home are included in the cause of death aspects in the present study $[14,21]$.

\section{Intervention}

The intervention group received interdisciplinary CGAbased care at an ambulatory geriatric unit in addition to usual care. The frequency of care given by the ambulatory geriatric unit was dependent on the patient's needs. The control group received usual care in the primary care unit or hospital [22].

\section{Data collection}

In both parts of the study, background data (gender, age, and living alone) were collected from the EMRs. In the cause of death part of the study, all EMRs from baseline to the death of each participant were examined according to cause of death and place of death. When looking at the stated causes of death, we compared these with the known facts about the last days of the person's life, thereby validating the reported cause of death.

The causes of death were divided into groups based on the ICD 10 classification, with a few exceptions. Different bacterial infections such as pneumonia and urinary tract infection were put in the infectious disease group (in the ICD 10, they are sorted under their different organs) and the participants that had "deterioration", "worsened general condition", "weakness because of age", and multi-morbidity as cause of death were put into a new group that we called "Death because of multifunctional decline", see Fig. 2.

In the palliative care part of the study, all EMRs from baseline to the death of the participants were examined according to the frequency of support from/referral to a specialised palliative care unit. The other palliative care aspects were examined for those participants that were assessed by a physician as dying. The palliative care aspects that were scrutinised were chosen according to the Swedish National Board of Health and Welfare indicators of good palliative care [24]; accomplished break point assessment [25]; information to patient/relatives about the change in care goals; and finally inventory and documentation of the presence of pressure ulcers during the last week of life (Fig. 3). As it was difficult to find out from the journals which grade the ulcers had, all grades (1-4) were taken to indicate the presence of an ulcer even though grade 1 is normally not taken into account when assessing the quality of care. When the records were reviewed according to given information about 
Fig. 1 Flowchart according to the original RCT with the present study's participants marked with \#. Superscript letter a indicates exclusion criteria: declined participation/moved to institution or died during inclusion period/unavailable. Superscript letter $b$ indicates did not take part in intervention despite acceptance and randomization. Superscript letter $\mathrm{c}$ indicates no information at all in the EMR about the death. Superscript letter $\mathrm{d}$ indicates moving to nursing home and, therefore, excluded from the palliative part. Included in the 36-month follow-up of causes of death

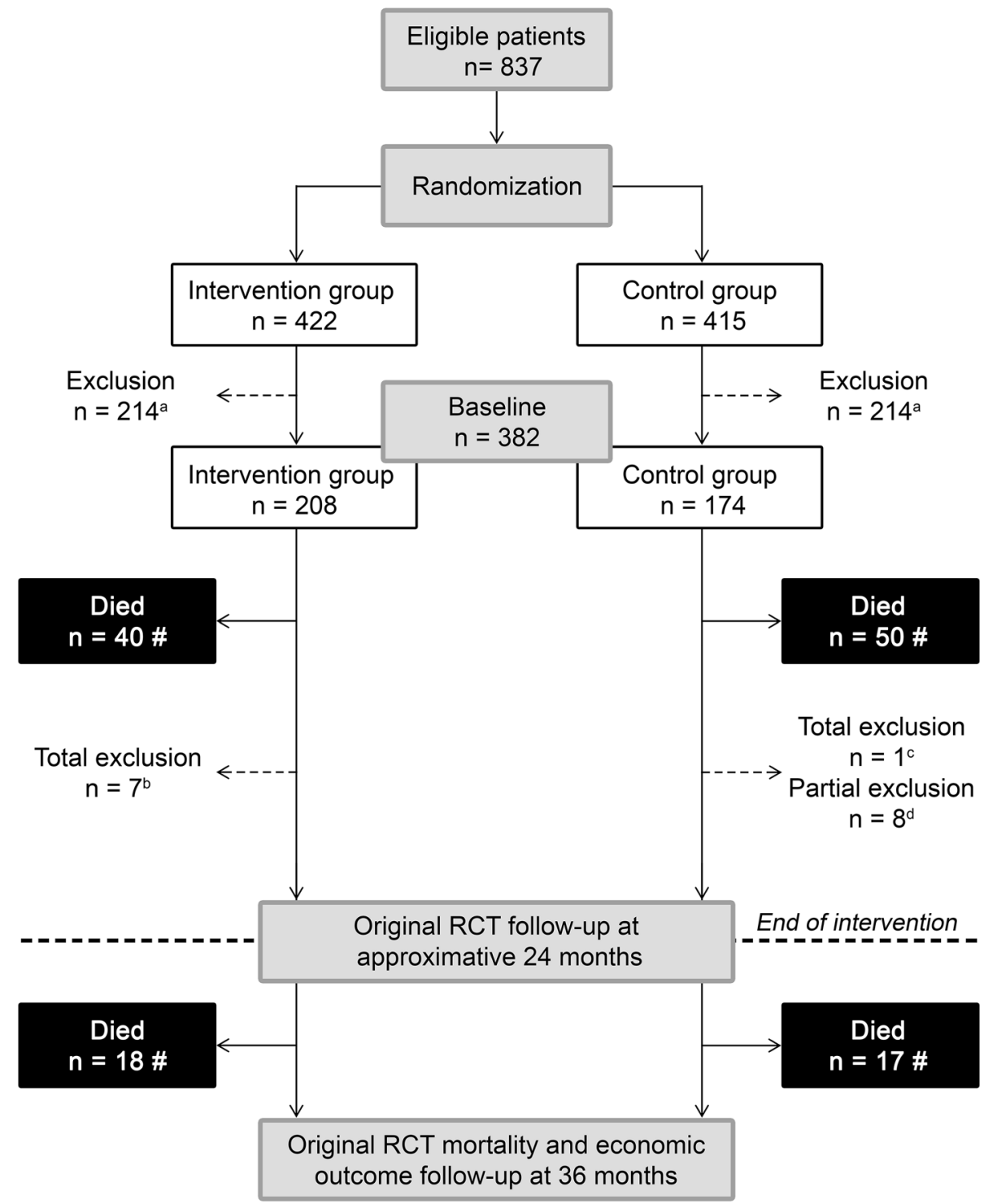

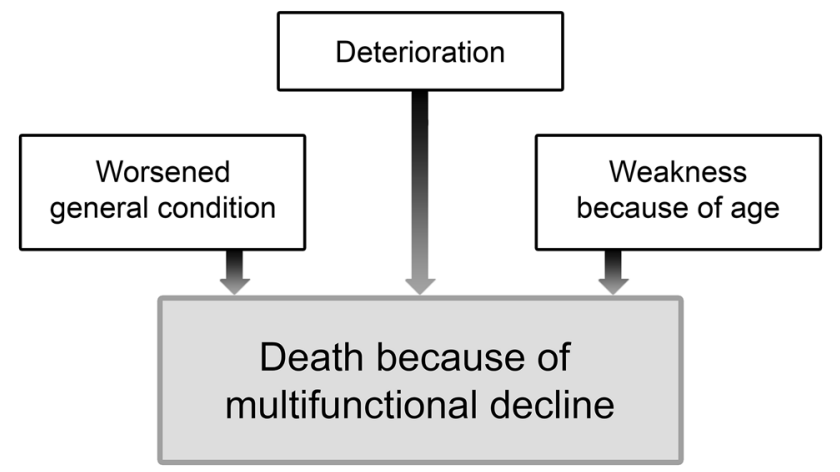

Fig. 2 Death because of multifunctional decline
All EMRs were analyzed regarding referral to specialized palliative care or not.

All EMRs were analyzed regarding whether the participant was assessed as dying by a doctor or not.

If the participant was assessed as dying the EMR was analyzed regarding the Swedish National Board of Health and Welfare indicators of good palliative care:

- Accomplished break point assessment.

- Information to patient about the change in care goals.

- Information to relatives about the change in care goals.

- Inventory and documentation of the presence of pressure ulcers in the last week of life.

Fig. 3 Quality of palliative care of those participants that died during the intervention period (up to 24 months) 
the new care goals, the data were set to "yes" if it was clear in the journal that the patient/relative had had a dialogue with a physician or a nurse. It was set to "no" if the records had a stated 'no' or if it was unclearly documented. In this subanalysis, we did not investigate symptom control.

The examination of records was conducted by the first author (JD) who extracted data systematically according to the present parameters. When there were uncertainties about the interpretation of the text, the whole research group took part in the decision.

\section{Statistical analysis}

Descriptive and comparative statistics were used on the data recorded from the two groups. The compared parameters were mainly nominal data, so the significance was calculated with a Chi-square test. For data at ratio scale, mean value and standard deviation were calculated and an independent samples $T$ test was carried out. Logistic regression was used to determine any impact of confounders which was of importance as the present study group was a sub group of the original randomised group. Statistical significance was set at $p<0.05$. IBM SPSS Statistics version 25 was used for statistical calculations.

\section{Results}

In total, 117 participants died in the original study up to 36 months from inclusion (IG $N=51 / \mathrm{CG} N=66$ ), while 74 participants died during the intervention period of 24 months (IG $N=33 / \mathrm{CG} N=41$ ). There was no statistical difference regarding the background data between the groups (Table 1).

\section{Follow-up at 36 months: death cause, place of death}

In summary, circulatory diseases were the most common cause of death at over $40 \%$ in both groups (IG $47.1 \%$ / CG $42.4 \%$ ) followed by cancer (IG 21.6\%/CG $15.2 \%$ ) and infections (IG 17.6\%/CG 12.1\%). "Multifunctional decline" was the cause of death in $3.9 \%$ of the cases in the intervention group and $7.6 \%$ in the control group. The causes of death are shown in Fig. 4. The data were too diverse and the sample too small to conduct any analyses to find statistically significant differences between the groups.

The participants died at different places: in their homes (IG 20\%/CG 18.2\%), at nursing homes (IG 24\%/CG $33.3 \%$ ) and in hospital (IG 56\%/CG 48.5\%). No statistically significant difference was shown between the groups $(p=0.547)$. One participant's data were missing due to lack of information in the records (IG $N=50 / \mathrm{CG} N=66$ ).

\section{Follow-up at 24 months: palliative care}

Regarding the palliative care given to participants dying during the 24 months of intervention, there was a statistically significant higher degree of support from a specialised palliative care unit in the intervention group (IG $30.3 \% / C G 7.3 \%, p=0.010$ ) (Table 2 ). There was no significant difference between the groups in the frequency with which the participants were assessed as dying by a physician (IG 72.7\%/CG 61.0\%, $p=0.288$ ).

Of all participants that were assessed as dying, a break point assessment was made with no difference between the groups (IG $66.7 \% / \mathrm{CG} 48 \%, p=0.187$ ). The information about new goals in the care was given to a higher degree to the relatives or related persons (IG $91.7 \% / \mathrm{CG}$ $88 \%, p=0.672$ ) but to less than half of the patients in total (IG 54.2\%/CG 36\%, $p=0.201$ ). There was no difference between the presence of pressure ulcers between the two groups (IG 33.3\%/CG 20\% $p=0.359$ ) and there were no differences in the documentation of pressure ulcer inventory (IG 70.8\%/CG 52\%, $p=0.145$ ) (Table 2).
Table 1 Background data for 36 and 24 months

\begin{tabular}{lllll}
\hline & All & Intervention group & Control group & Significance \\
\hline 36 months & $N=117$ & $N=51$ & $N=66$ & $p<0.05$ \\
Women, $N(\%)$ & $44(37.6)$ & $21(41.2)$ & $23(34.8)$ & 0.483 \\
Age (years) mean (SD) & $83.6(4.9)$ & $83.5(4.5)$ & $83.7(5.2)$ & 0.796 \\
Living alone, $N(\%)$ & $59(50.9)^{\mathrm{a}}$ & $25(50)$ & $34(51.1)^{\mathrm{a}}$ & 0.872 \\
24 months & $N=74$ & $N=33$ & $N=41$ & $p<0.05$ \\
Women, $N(\%)$ & $21(28.4)$ & $9(27.3)$ & $12(29.3)$ & 0.850 \\
Age (years) mean (SD) & $82.9(4.9)$ & $82.7(4.4)$ & $83.1(5.3)$ & 0.677 \\
Living alone, $N(\%)$ & $32(43.8)$ & $16(50.0)$ & $16(39.0)$ & 0.348 \\
\hline
\end{tabular}

${ }^{a}$ One participant missing because of lack of information in the EMR 
Fig. 4 Causes of death (in \%) within the Intervention and Control groups

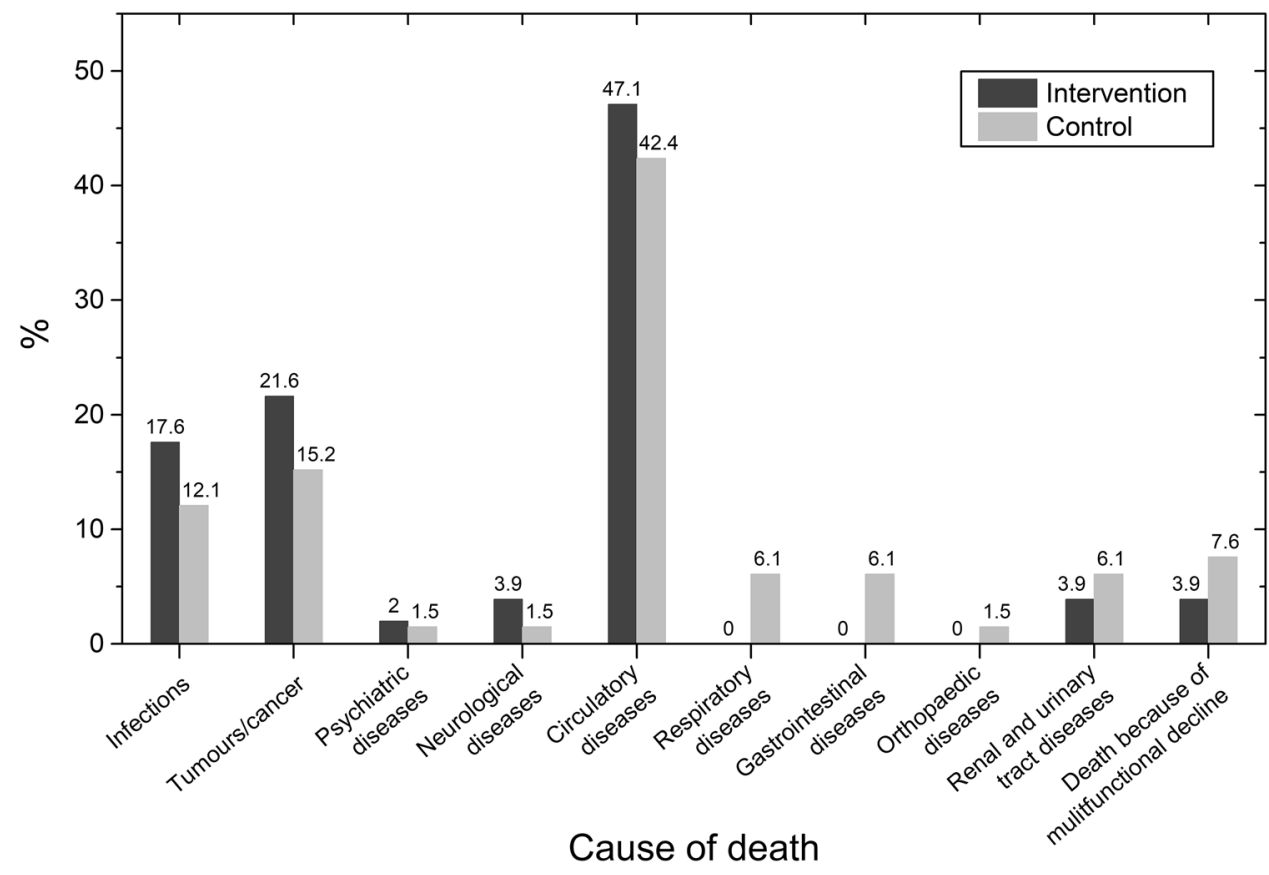

Table 2 Specialised palliative care and indicators of good palliative care

\begin{tabular}{|c|c|c|c|c|}
\hline & All & $\begin{array}{l}\text { Intervention group } \\
\text { (IG) }\end{array}$ & Control group (CG) & Significance \\
\hline & $N=74^{\mathrm{a}}$ & $N=33$ & $N=41$ & $p<0.05$ \\
\hline \multirow[t]{2}{*}{ Specialised palliative care unit, $N(\%)$} & $13(17.6)$ & $10(30.3)$ & $3(7.3)$ & 0.010 \\
\hline & $N=49^{\mathrm{b}}$ & $N=24$ & $N=25$ & $p<0.05$ \\
\hline Break point assessment, $N(\%)$ & $28(57.1)$ & $16(66.7)$ & $12(48.0)$ & 0.187 \\
\hline Information given to patient, $N(\%)$ & $22(44.9)$ & $13(54.2)$ & $9(36.0)$ & 0.201 \\
\hline Information given to related person, $N(\%)$ & $44(89.8)$ & $22(91.7)$ & $22(88.0)$ & 0.672 \\
\hline $\begin{array}{l}\text { Documentation of skin assessment regarding pressure } \\
\text { ulcers, } N(\%)\end{array}$ & $30(61.2)$ & $17(70.8)$ & $13(52)$ & 0.176 \\
\hline Presence of pressure ulcers-grade $1-4, \mathrm{~N}(\%)$ & $13(26.5)$ & $8(33.3)$ & $5(20)$ & 0.359 \\
\hline
\end{tabular}

No confounding factor was found when using logistic regression

${ }^{a}$ All patients up to 24 months

${ }^{\mathrm{b}}$ All patients up to 24 months that were assessed as dying

\section{Discussion}

We found a statistically significant difference between CGA-based care and ordinary care when it came to referral to specialised palliative care clinics. The other investigated parameters did not show any significant results.

The causes of death in this study follow the European pattern of causes of death, where circulatory diseases stand for the largest group followed by cancer diseases and respiratory diseases [1]. In this material, we categorised common bacterial infections in the infection group, which is why that group is larger than the respiratory diseases group, mainly due to pneumonia and urinary tract infections which are common among old people. The study did not find any surprising differences in cause of death between the intervention group and control group that could explain the reduced mortality.

It was interesting to find out that the intervention group had a higher degree of support from the specialised palliative care team. That could be an effect of higher referral from the CGA team to the specialised palliative unit due to greater attention to palliative needs in the intervention group. As it is difficult to predict death when patients follow an entryreentry pattern [16] and CGA is intended to take care of the totality and thus has many similarities to traditional 
palliative care, CGA-based care might recognise who is suitable for specialised palliative care to a higher degree. This is in line with the opinion that specialised palliative care should also reach patients with non-malignant diseases [17]. It is surprising though that there was no difference between the groups in break point assessments or information given about the care goals. The lack of significant data in many of the palliative questions is probably a result of the subanalysis being underpowered rather than the specialised palliative care being insufficient. With a well-powered original study, it might had been possible to see effect not only in referral to specialised palliative care but also in the palliative indicators. It may also be a result of not including patients living in nursing homes which usually means an increase in geriatric syndromes and frailty [26-28] in whom CGA is more effective [27, 29].

This study is a subanalysis which is a limitation, as is the low number of participants. The results would have been more generalisable if there had been more participants and if these outcomes had been measured as primary outcomes prospectively in an originally RCT. The original RCT was well powered for its outcomes, but for this outcome, it was underpowered. It is a strength that the causes of death were not just taken from the diagnosis statistics of the health care system, but were examined in depth to improve their validity. In an original study, it had been possible to investigate quality of life, symptom control, and functional decline which are examples of other important areas of the palliative care effectiveness. This was impossible in this subanalysis and is a weakness of the study, especially when symptom control is one of the main goals in palliative care. There are studies that use CGA to investigate the patient status when important decisions are to be made, e.g., to get measures to decide whether the patient will withstand oncological treatment or if it is time to initiate a break point dialogue [30,31], but no studies were found, where CGA was used to investigate the palliative needs and become a basis to improve the palliative treatment. This study is, as far as we know, the first to investigate the effect of CGA on causes of death and CGA aspects of palliative investigation, which makes it unique and increases its importance.

\section{Conclusion}

The present study in an outpatient context cannot prove any effects of CGA on causes of death that could explain the effect of CGA on mortality. The study shows that CGA in outpatient care means a higher rate of specialised palliative care but the study cannot show any effects on the palliative quality parameters measured. Further studies with statistical power are needed.
Acknowledgements Statistician Johan Lyth at the Research and Development Unit in Region Östergötland assisted with statistical support. The text was proofread by an English native speaking professional at the agency Anchor English.

Funding This study was funded with Grants directed to Vrinnevi Hospital, Region Östergötland from the Agreements Concerning research and education of doctors and with Grants from the Local Health Care Eastern Östergötland.

\section{Compliance with ethical standards}

Conflict of interest None to report.

Ethical approval The original study received approval from the regional ethical review board at Linköping University Dnr 2011/4131. For the subanalysis of the actual study, no approval was needed, because the persons were deceased. However, the regional ethical review board at Linköping University gave an advisory opinion Dnr 2017/229-31 and found nothing to object to.

Informed consent All the patients had given their informed consent for participation in the original RCT according to the Helsinki declaration.

Open Access This article is distributed under the terms of the Creative Commons Attribution 4.0 International License (http://creativeco mmons.org/licenses/by/4.0/), which permits unrestricted use, distribution, and reproduction in any medium, provided you give appropriate credit to the original author(s) and the source, provide a link to the Creative Commons license, and indicate if changes were made.

\section{References}

1. Eurostat (2017) Causes of death statistics-people over 65. Eurostat Statistics Explained. https://ec.europa.eu/eurostat/stati stics-explained/index.php/Causes_of_death_statistics_-_peopl e_over_65. Accessed 5 Dec 2017

2. Rubenstein LZ, Stuck AE, Siu AL, Wieland GD (1991) Impacts of geriatric evaluation and management programs on defined outcomes: overview of the evidence. J Am Geriatr Soc 39:8S-16S

3. Parker SG, McCue P, Phelps K, McCleod A, Arora S, Nockels K et al (2018) What is comprehensive geriatric assessment (CGA)? An umbrella review. Age Ageing 47(1):149-155. https://doi. org/10.1093/ageing/afx166

4. Choi JY, Cho KJ, Kim SW, Yoon SJ, Kang MG, Kim KI et al (2017) Prediction of mortality and postoperative complications using the hip-multidimensional frailty score in elderly patients with hip fracture. Sci Rep 7:42966. https://doi.org/10.1038/srep4 2966

5. Bureau ML, Liuu E, Christiaens L, Pilotto A, Mergy J, Bellarbre $F$ et al (2017) Using a multidimensional prognostic index (MPI) based on comprehensive geriatric assessment (CGA) to predict mortality in elderly undergoing transcatheter aortic valve implantation. Int J Cardiol 236:381-386. https://doi.org/10.1016/j.ijcar d.2017.02.048

6. Avelino-Silva TJ, Farfel JM, Curiati JA, Amaral JR, Campora F, Jacob-Filho W (2014) Comprehensive geriatric assessment predicts mortality and adverse outcomes in hospitalized older adults. BMC Geriatr 14(1):129. https://doi. org/10.1186/1471-2318-14-129 
7. Deschodt M, Flamaing J, Haentjens P, Boonen S, Milisen K (2013) Impact of geriatric consultation teams on clinical outcome in acute hospitals: a systematic review and meta-analysis. BMC Med 11(1):48. https://doi.org/10.1186/1741-7015-11-48

8. Ellis G, Gardner M, Tsiachristas A, Langhorne P, Burke O, Harwood RH et al (2017) Comprehensive geriatric assessment for older adults admitted to hospital. Cochrane Database Syst Rev. https://doi.org/10.1002/14651858.cd006211.pub3

9. Ellis G, Whitehead MA, Robinson D, O'Neill D, Langhorne P (2011) Comprehensive geriatric assessment for older adults admitted to hospital: Meta-analysis of randomised controlled trials. BMJ (Online). https://doi.org/10.1136/bmj.d6553

10. Saltvedt I, Mo ESO, Fayers P, Kaasa S, Sletvold O (2002) Reduced mortality in treating acutely sick, frail older patients in a geriatric evaluation and management unit. A prospective randomized trial. J Am Geriatr Soc 50(5):792-798. https://doi.org/10 $.1046 / \mathrm{j} .1532-5415.2002 .50202 . x$

11. Stuck AE, Siu AL, Wieland GD, Rubenstein LZ, Adams J (1993) Comprehensive geriatric assessment: a meta-analysis of controlled trials. Lancet 342(8878):1032-1036. https://doi. org/10.1016/0140-6736(93)92884-v

12. Boult C, Boult LB, Morishita L, Dowd B, Kane RL, Urdangarin CF (2001) A randomized clinical trial of outpatient geriatric evaluation and management. J Am Geriatr Soc 49(4):351-359. https://doi.org/10.1046/j.1532-5415.2001.49076.x

13. Van Grootven B, Flamaing J, Dierckx de Casterle B, Dubois C, Fagard K, Herregods MC et al (2017) Effectiveness of in-hospital geriatric co-management: a systematic review and meta-analysis. Age Ageing 46(6):903-910. https://doi.org/10.1093/ageing/afx05 1

14. Ekdahl AW, Alwin J, Eckerblad J, Husberg M, Jaarsma T, Mazya AL et al (2016) Long-term evaluation of the ambulatory geriatric assessment: a frailty intervention trial (AGe-FIT): clinical outcomes and total costs after 36 months. J Am Med Dir Assoc 17(3):263-268. https://doi.org/10.1016/j.jamda.2015.12.008

15. WHO (2018) Definition of Palliative Care. https://www.who.int/ cancer/palliative/definition/en/. Accessed 14 Nov 2018

16. Murtagh FEM, Preston M, Higginson I (2004) Patterns of dying: palliative care for non-malignant disease. Clin Med 4(1):39-44. https://doi.org/10.7861/clinmedicine.4-1-39

17. Addington-Hall J, Fakhoury W, McCarthy M (1998) Specialist palliative care in nonmalignant disease. Palliat Med 12(6):417427. https://doi.org/10.1191/026921698676924076

18. Eckerblad J, Theander K, Ekdahl A, Unosson M, Wirehn AB, Milberg A et al (2015) Symptom burden in community-dwelling older people with multimorbidity: a cross-sectional study. BMC Geriatr 15(1):1. https://doi.org/10.1186/1471-2318-15-1

19. Eckerblad J, Theander K, Ekdahl AW, Jaarsma T (2016) Symptom trajectory and symptom burden in older people with multimorbidity, secondary outcome from the RCT AGe-FIT study. J Adv Nurs 72(11):2773-2783. https://doi.org/10.1111/jan.13032

20. Lindskog M, Tavelin B, Lundstrm S (2015) Old age as risk indicator for poor end-of-life care quality - a population-based study of cancer deaths from the Swedish Register of Palliative Care. Eur J Cancer 51(10):1331-1339. https://doi.org/10.1016/j. ejca.2015.04.001

21. Ekdahl AW, Wirehn AB, Alwin J, Jaarsma T, Unosson M, Husberg $\mathrm{M}$ et al (2015) Costs and effects of an ambulatory geriatric unit (the AGe-FIT study): a randomized controlled trial. J Am Med Dir Assoc 16(6):497-503. https://doi.org/10.1016/j.jamda .2015.01.074

22. Mazya AL, Eckerblad J, Jaarsma T, Hellstrm I, Krevers B, Milberg A et al (2013) The ambulatory geriatric assessment-a frailty intervention trial (AGe-FIT) - a randomised controlled trial aimed to prevent hospital readmissions and functional deterioration in high risk older adults: a study protocol. Eur Geriatr Med 4(4):242-247. https://doi.org/10.1016/j.eurger.2013.05.004

23. Brody T (2016) Clinical trials, 2nd edn. Academic Press, New York

24. Nationellt kunskapsstöd för god palliativ vård i livets slutskede (2013) Vägledning, rekommendationer och indikatorer. Stöd för styrning och ledning. The National Board of Health and Welfare, Stockholm, pp 61-67

25. The National Board of Health and Welfare (2011) Brytpunkt vid övergång till palliativ vård $\mathrm{i}$ livets slutskede (Break point when transferring to end of life palliative care). http://termbank.socia 1styrelsen.se/?TermId=479\&SrcLang=sv. Accessed 13 June 2018

26. Bandeen-Roche K, Seplaki CL, Huang J, Buta B, Kalyani RR, Varadhan $R$ et al (2015) Frailty in older adults: a nationally representative profile in the United States. J Gerontol A Biol Sci Med Sci 70(11):1427-1434. https://doi.org/10.1093/gerona/glv133

27. Clegg A, Young J, Iliffe S, Rikkert MO, Rockwood K (2013) Frailty in elderly people. Lancet 381(9868):752-762. https://doi. org/10.1016/s0140-6736(12)62167-9

28. Kojima G (2015) Prevalence of frailty in nursing homes: a systematic review and meta-analysis. J Am Med Dir Assoc. 16(11):940 945. https://doi.org/10.1016/j.jamda.2015.06.025

29. Ekdahl AW, Sjöstrand F, Ehrenberg A, Oredsson S, Stavenow L, Wisten A et al (2015) Frailty and comprehensive geriatric assessment organized as CGA-ward or CGA-consult for older adult patients in the acute care setting: a systematic review and metaanalysis. Eur Geriatr Med 6(6):523-540. https://doi.org/10.1016/j. eurger.2015.10.007

30. Baronner A, MacKenzie A (2017) Using geriatric assessment strategies to lead end-of-life care discussions. Curr Oncol Rep 19(11):75. https://doi.org/10.1007/s11912-017-0631-4

31. Maas HAAM, Janssen-Heijnen MLGA (2007) Comprehensive geriatric assessment and its clinical impact in oncology. Eur J Cancer 43(15):2161-2169. https://doi.org/10.1016/j.ejca.2007.08.002

Publisher's Note Springer Nature remains neutral with regard to jurisdictional claims in published maps and institutional affiliations. 